\title{
The Role of English in the Acquisition of Intercultural Competence by Russian Students
}

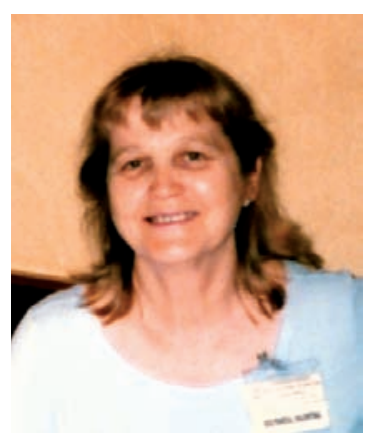

Valentina Golysheva

\section{Introduction}

Since we use language differently, our lives are shaped

Sby the way we use it. It is necessary for students of foreign languages to examine the interaction between language and social behaviour. The end of the $20^{\text {th }}$ century and the beginning of the $21^{\text {st }}$ century are marked by the extensive development of cultural ties and great interest in research into language and sociocultural context. The interaction of language and social behavior is becoming of prime interest in linguistics. Scholars look upon language from the point of view of its function, i.e., how it can be used for specific purposes. They are becoming more and more interested in various speech activities. As a result, a new branch of linguistics - Pragmalinguistics has emerged. Language is being looked upon as an instrument of social power, with the main questions being: "How to do things with words?" and "How does language influence social behavior and human mentality?" (i.e. how the human factor influences language). Teaching Russian students an elementary, stereotyped form of social behaviour typical of people in English-speaking communities requires that academic priority be given to teaching patterns of speech and ways of manipulating language for specific purposes. For instance, Western pragmatism and advertising enthusiasm are fully reflected in everyday speech. When the English need a piece of advice, they often use emotively coloured words like wonderful, amazing, great, fantastic, incredible, smashing, sensational, brilliant, etc. Thus, the advice is turned into an idea which is sold without a hard shell, and the "customer" takes the bait.

Russian students should be motivated to acquire intercultural competence in the English context by investigating the disparities in language use and in cultures/mentalities. Thus, the phrase "Don't touch the dog, darling. It may not be friendly", sounds very unusual to the Russian speaker who would hardly ever associate the image of a dog with friendliness in a similar situation, but rather with aggressiveness. We checked the reaction of Russian speakers to the image of a dog. It turned out that most Russians would say to the kid "Don't touch the dog, darling. It may bite you." So, one of the challenges for Russian students within an English context is investigating disparities in language use which are culturally determined. To avoid any misunderstanding in intercultural relationships, Russian students should primarily be given an explicit statement of English values and ethos. Karen Hewitt, in her book "Understanding Britain", which is specially written for the Russian reader, gives a few 
generalizations about the British and their social priorities. Hewitt observes: "Naturally, they will not be true for everyone, but they are common attitudes which sometimes distinguish us significantly from other Western countries. If you talk to parents of all social groups, you will find there is a general agreement that children should be taught to be kind, to be honest and to be fair; and that it is wrong to be cruel, to steal or to destroy the happiness of other people. Children should also learn to be loyal to their own group" (2002: 83).

\section{Politeness Strategy}

How do parents in Britain teach their children the difference between "right" and "wrong"; how do they teach their children to behave morally? One of the most distinct features of English culture is the ability of people to observe the politeness strategy. People in English-speaking communities tend to encourage tact, sympathy and respect for other people. Scarrot comments on the politeness strategy in English social behaviour: "In today's mad world, politeness is more important than ever...being polite and considerate should be a top priority" (2000: 49). Social priorities in the Englishspeaking communities are clearly reflected in their language (see, Jones, 1989; Blundell, 1992). On the basis of the functional approach to language, a great number of works have appeared on the theory of politeness of speech. The numerous authors supporting this theory have successfully developed a typology of speech acts - their cognitive status, cultural dependence and speech norms (see the review of papers by Kasper, 1990, 2001). It is already axiomatic that "any language reflects the culture and mentality and it is vividly seen in the speech etiquette" (Wierzbicka, 1990).

Politeness and respect are deeply rooted in the British governmental policies for educational institutions. The mass media give wide coverage to the question of ethics at school. For instance, the Guardian, in one of its leading articles "Ethics in Schools", emphasizes that "A key government adviser addresses a conference of secondary school head teachers and talks about the need to ensure children not only achieve good academic standards, but also a highly developed sense of ethics"(1998, 17). Schools in English-speaking communities pledge themselves to such moral values as honesty, respect for others, compassion and justice.

For example, a Parent's Handbook, (Forfar Academy, Scotland), commenting on pupils' spiritual, moral and cultural values, states: "It is a fundamental principle of our school that all who are involved in the life of our school, both have a right to be respected as individuals and carry responsibility to act in a considerate and respectful manner towards others" $(1995,19)$.

It is indisputable that the task of a foreign language teacher is to examine the extent to which language communities differ in their application of the politeness principle - PP. It might be of interest to show by the example of several different situations how widely speech etiquette varies in the English and Russian communities.

- When the Russian guest is a little slow in the morning and fails to be in time for breakfast, the wife in the host family may invite the guest in an extremely polite way, avoiding a direct injunction: "It's been decided that you should be ready for breakfast." In the Russian family it's quite possible to hear the imperative phrase 
like "Why don't you go for breakfast? Hurry up! You keep everybody waiting for you". When an English wife doesn't like the idea that her husband is going to water the flowers in the garden in the heat, she might say in a very evasive way, "You don't want to water the flowers now, darling". The Russians will most probably use the negative imperative "Don't water the flowers now! or "You mustn't water the flowers now!"

- The English mother always finds a good reason to make her child help her about the house: "Please, could you just wash the things up? I am so tired". This request sounds less imperative than the one made in a Russian home: the child is not asked but is usually given an imperative command, "Ann, go and wash up the dishes at once".

- The English, when discussing their employment with somebody, try to avoid the direct question of payment: "Is your sister well-paid? How is it from the money point of view?" In the same situation the Russians will ask directly: "How much does your sister earn? What is her salary?"

So the politeness strategy in British culture, as well as the diversity of its verbal expression, might be of inestimable value to the Russian students of English. One of the striking features of English social behaviour in terms of verbal politeness is the ability to avoid direct imposition either in conditional requests or in public imperatives. It might be of interest to illustrate this principle.

\subsection{Conditional Requests}

To begin with, people in English-speaking cultures are very sophisticated in expressing requests in a most polite way. Thus the sentence "Can't you give me your book?" sounds to the English somewhat impolite and even aggressive because of the negation in it (which is a norm for Russian). In this case the English-speaking person will try and mask the imposition by employing a variety of indirect illocutions:

Can I ask you to give me your book?

Could I ask you...?

Could I possibly ask you...?

I wonder if you could give me ...?

I wonder if you could possibly give me...?

Would it be all right / o' kay, if I ask you...?

I hope you don't mind my asking you....? etc.

Politeness strategy exploits here the Maxim of Relation (a 'hinting strategy' according to Leech, 1983). As we see, in English-speaking communities people tend to be more apologetic and prefer not to reveal their true feelings, but mask them instead with verbal politeness. In reference to the example given above, teachers of English have to explain to the Russian students that requests given in the negative form may sound impolite and even sarcastic to an Englishman. It might be interesting to note that an English-speaking person is likely to use the 1st person singular in his request (Can I...?), taking the problem on himself. In contrast, the Russian speaker gets the 
addressee/interlocutor involved in his problem by using second person singular in his request (Can't you?). In fact, it is a Face Threatening Act (FTA, for details see, Brown and Levinson, 1994), because the request is expressed directly. It is quite important for the Russian student of English to realize that lack of politeness strategy in his speech may be associated with aggressiveness by the members of the English-speaking community.

\subsection{Public Imperatives}

Due to the politeness strategy actively employed by English-speaking people in verbal communication, most officials tend to make their notices and announcements sound less imperative:

In the interest of security, visitors to school are required to wear a badge of identification. Thank you for your co-operation. We are a non-smoking school. Your co-operation is much appreciated.

The strategy of disguised imperatives is extremely popular in announcements for most public places, like cafes, restaurants, movies, museums, gyms, pubs, etc. They usually illustrate an amazing variety of verbal expressions carrying implicit imposition:

Thank you for not smoking in this area.

In the interest of hygiene. No Dogs.

Please, ask before bringing in pushchairs, buggies, etc. Thank you.

Please, could gentlemen wear shirts or a top while in this restaurant. Thank you.

You must be 16 to buy alcohol. Most English pubs don't welcome under 18's.

Some owners of stores and cafes display a sense of humour and their verbose notices can evoke a smile:

With immediate effect. This store will not sell alcohol to persons fortunate enough to look under 21 years of age, unless proof of age shows they are over 18. This is company policy (a store in Streatley and Goring).

It is required by law that dog mess must be cleared from paths, roads, grass and the beach. Hornsea and dogs deserve a better image (Hornsea, Yorkshire).

Please, ensure you are showered and suitably dressed before using the bar (Bistro in Wootton, Bedford).

It must be admitted that the only exception are the direct imperatives accounting for security needs: Kill your speed! Mind the step! Beware of the dog!, etc.

Such imperatives may even contain strong but justified epithets like: Don't be an idiot! Keep off the railways! (Edinburgh railway station)

\section{Euphemisms}

To avoid offensive overtones or refusal, the English also tend to use subtle euphemisms, the so-called periphrastic expressions that make the implicit imposition or 
request sound milder, vaguer, less blunt or disagreeable. One can often see a very subtle notice in cathedrals and museums which encourages visitors to pay admission money:

(1) All the exhibitions in the Portrait Gallery this year are free, but they cost money to mount. If you enjoyed this exhibition and would like to support the gallery and its activities, your contribution would be much appreciated (Portrait Gallery, Edinburgh).

(2) Inside York Minster there used to be a two-sided poster which was publicly displayed at the entrance. It contained two notices which skilfully masked the notion of raising the fund with admission money. One notice was supposed to be read when you entered the cathedral and the one when you left it. On entrance: We make no charge for entry. Please, help us to maintain York Minster by donating 2 pounds. On exit: We hope you are inspired by your visit to the great Cathedral. Please, leave a gift if you haven't done so already.

As we see, the administration prefers to use euphemisms like donation and contribution, as well as the periphrastic expression to leave a gift. Such mild expressions certainly have their impact on the visitors, and as a result, they are ready to leave some extra money in the Cathedral.

Euphemistic language also reveals social attitudes. It seeks to put a finer gloss on relationships and it may be referred to as a social jargon (buzz words) or taboos (Auto, 1993).

(3) We thank you for cooperation in refraining from smoking or talking loudly during the performance, as it may offend other patrons (cinema in Hull).

As can be seen from the notice, the imperative is again skilfully disguised here. The effect of mild imposition is achieved due to the combination of official style and a periphrastic expression: the words refraining and cooperation are used together with the euphemism patron. The role of this euphemism is to upgrade the social status and selfrespect of the visitor to the movies. The whole request sounds less blunt and disagreeable. At least the visitor is not irritated by the implicit imposition, i.e. when he/she is enforced/pushed to comply with the rules of the public place. Obviously, there are psychological reasons for the way English-speaking people formulate thoughts, being aware of how they sound. This basically concerns instructive information. People do not appreciate being told what to do.

\section{Functions of Euphemisms}

The use of euphemisms is widely discussed in the theory of language planning, socalled Political Correctness (see the origin of the term and concept of "political correctness" (PC) in Cameron, 1994; 1995; Christian, 1993). Verbal politeness in English presupposes two main functions of euphemisms: they may be used either for achieving a positive effect of the message conveyed or upgrading the social status of people. In fact, most people in English-speaking communities prefer to use words with 
preferably positive evaluative overtones. This positive tendency is one of the social priorities of the English-speaking countries. In order to achieve a positive effect, words with negative connotations are usually avoided by English-speaking people in their speech and are replaced by euphemisms instead. This process is usually observed in everyday life ("the dog may not be friendly") as well as in some particular spheres, such as politics (Non-British citizens instead of foreigners).

The following dialogue between a Russian customer and the owner of a clothing shop in Belfast may serve as a typical example of the use of euphemisms in everyday life:

(4) Customer: "Do you have any cheap fabric?

Owner: "Yes, we've got plenty of inexpensive stuff".

One and the same notion of fabric is given a different nomination due to the evaluative qualifiers. But the variant inexpensive stuff is preferable for the native speaker because of its positive colouring as compared with the notion "cheap". It is the so-called sugar-coated statement which neutralizes the negative connotation of the nomination. For instance, when a wife burns a piece of toast at breakfast, she may present it to her husband as a "well-done" toast just for fun. Or when an old lady gets a bus pass, she calls herself a senior citizen and gets a discount. In the sphere of politics, euphemisms are used very efficiently (see the review of the papers in Fairclough, 1998). For instance, when, the British ship "Antelope" sank during the Argentine crisis on 25 March 1982, this fact was commented on differently in the British media: Blaze of Glory (The Daily Mail); Senseless Sacrifice (Morning Star).

\section{References:}

1. Auto J. Euphemisms (DOE). London: Bloomsbury, 1993.

2. Blundell J., Higgens J., Middlemiss N. Function in English. Oxford University Press, 1992.

3. Brown Penelope, Levinson Stephen C. Politeness: Some Universals in Language Usage. Cambridge: Cambridge University Press, 1994.

4. Cameron D. Words, Words, Words: The Power of Language. // The War of the Words. / Ed. by Sarah Dunant. London: Virago, 1994.

5. Cameron D. Verbal Hygiene. London: Routledge, 1995.

6. Christian D. Language Planning: The View from Linguistics. // Linguistics, The Socio-Cultural Context. Cambridge University Press, 1993.

7. Davis A. Politicized Language. // Concise Encyclopedia of Sociolinguistics. / Ed. by Rajend Mesthrie. Oxford: Elsevier Ltd., 2001.

8. Ethics in School. // "Guardian". 24.03.1998.

9. Fairclough N. Power and Language. // Concise Encyclopedia of Pragmatics. / Ed. by Jacob L. May. Oxford: Elsevier Ltd., 1998. 
10. Hewitt K. Understanding Britain. Perspective Publications Ltd, 2002.

11. Jones L., von Baeyer C. Functions of American English. // Communication Activities for the Classroom (Student's Book). Cambridge University Press, 1989.

12. Kasper G. Linguistic Politeness. // Journal of Pragmatics. North Holland, 1990, № 14.

13. Kasper G. Politeness. // Concise Encyclopedia of Sociolinguistics. / Ed. by Rajend Mesthrie. Oxford: Elsevier Ltd., 2001.

14. Leech G. Principles of Pragmatics. London - New York, 1983.

15. Pupils' Spiritual, Moral and Cultural Values. // Parent's Handbook. Scotland: Forfar Academy, 1995.

16. Scarrot T. Don't be silly, be polite. // Yorkshire Riding Magazine. June-July, 2000.

17. Wierzbicka A. Cross-Cultural Pragmatics. Berlin: Mouton de Gruyer, 1990.

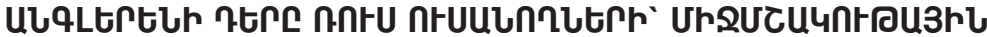

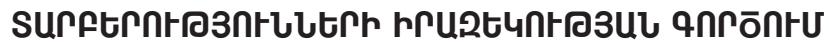

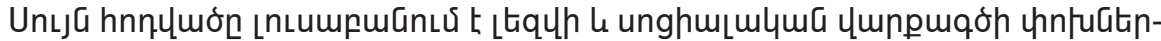

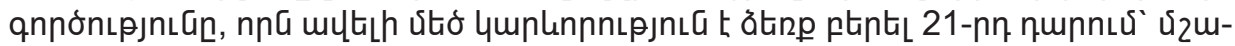

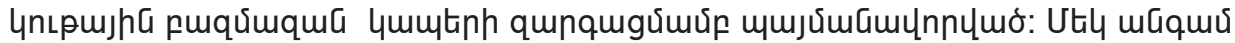

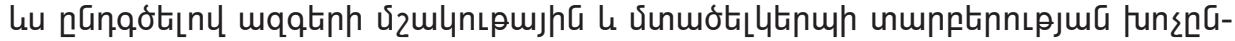

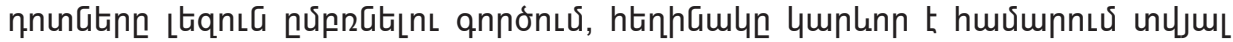

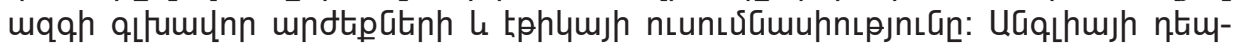

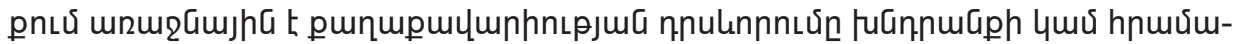

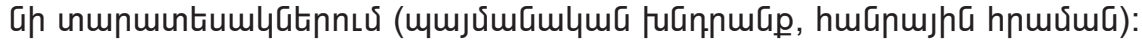

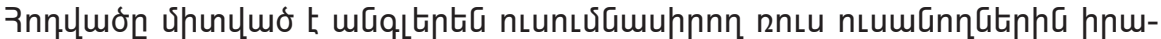

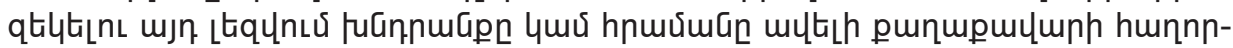

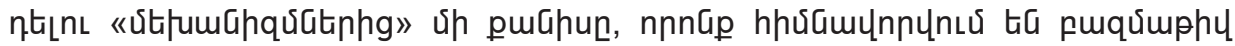

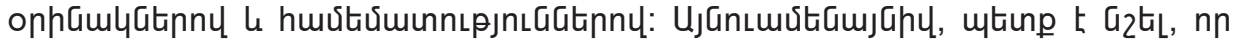

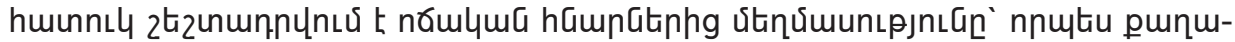
pulunh funuph lumlunn punumphs: 